Arch Virol (1998) 143: 1523-1534

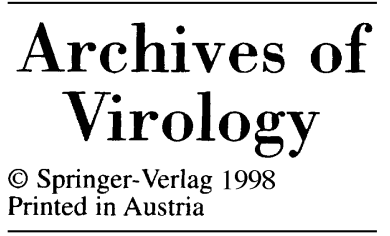

\title{
Haemagglutinin-esterase protein (HE) of murine corona virus: DVIM (diarrhea virus of infant mice)
}

\author{
K. Sugiyama, M. Kasai, S. Kato, H. Kasai, and K. Hatakeyama \\ Department of Biology, Faculty of Science, Hirosaki University, Hirosaki, Japan
}

Accepted March 24, 1998

Summary. The acetylesterase (AE) activity of DVIM (diarrhea virus of infant mice) was assigned to the haemagglutinin-esterase (HE) protein. The substrate specificity was examined using the natural substrate bovine submaxillary mucin (BSM) and/or synthetic substrates p-nitrophenylacetate (p-NiA) and $\alpha$ naphthylacetate ( $\alpha-\mathrm{NA})$ and compared with several strains of MHV and influenza viruses. The AE of DVIM hydrolyzed the O-acetylester bond of BSM, and the two synthetic substrates $\mathrm{p}-\mathrm{NiA}$ and $\alpha-\mathrm{NA}$ in vitro. MHV-S reacted efficiently with both $\mathrm{p}-\mathrm{NiA}$ and $\alpha$-NA but less with BSM. Influenza virus (C/Miyagi/77) reacted with BSM efficiently, however reacted with p-NiA weakly, but not with $\alpha$-NA at all. Thus, the AE-reactivity of DVIM was distinctly different from that of MHV-S and influenza $C$ virus, suggesting that the AE of HE may have a modified function. Isolation of HE by the treatment with non ionic detergent NP40, resulted in globules approximately $5 \mathrm{~nm}$ in diameter. DVIM-binding proteins were demonstrated in the plasma membrane of mouse intestinal brush-border cells and hepatocytes. The same protein was recognized by MHV-S and MHV-4. The cell membranes obtained from these target tissues were substrates for the AE of DVIM. The biological importance of the HE protein for DVIM is discussed.

\section{Introduction}

Coronaviruses are enveloped viruses containing a single-stranded genomic RNA of positive polarity. The human coronavirus OC43 [4, 10, 11, 22, 28, 33] and bovine coronavirus (BCV) $[3,14,20,22,28,29]$ are known to possess both haemagglutinating (HA) and receptor-destroying enzyme (RDE) activities similar to influenza $C$ viruses $[6,9,12,21,27]$. The diarrhea virus of infant mice (DVIM) is an enterotropic mouse hepatitis virus (MHV) that was originally isolated and characterized by Sato and coworkers [15]. We reported previously that DVIM possesses both HA and RDE activities [23, 24] and has a strain specific glycoprotein (gp69) which forms a dimeric polypeptide gp140 by disulfide linkages [25]. 
Recently Gagneten and coworkers described DVIM uses biliary glycoprotein as a receptor for infection of cells as do other strains of MHV [7]. Morphologically, DVIM possesses short spike projections in addition to the club-shaped projections that are characteristic for coronaviruses [24]. While the M protein of other MHV strains has been shown to only contain O-linked charbohydrate side chains, the corresponding protein of DVIM has been demonstrated to contain both O-linked and N-linked oligosaccharides (unpubl. data). Similar to DVIM, BCV is also known to possess short spike projections and a disulfide-linked dimeric polypeptide, gp140, that can be converted by reducing agents to monomers of 65KDa [14]. Thus the morphological and biochemical similarities between DVIM and BCV suggest an evolutionary relationship between both viruses. The RDE of influenza $\mathrm{C}$ virus is an acetylesterase that releases the acetyl group from position C-9 of the N-acetyl-9-O-acetylneuraminic acid (Neu5,9Ac2). This enzyme activity is a function of the HEF protein [8]. The same enzyme activity has been assigned to the $\mathrm{HE}$ protein of BCV $[16,17]$. Both proteins are able to release acetate from sialic acid present on various glycoconjugates as well as from synthetic substrates $[6,8,9,16,27,28,30]$. It is therefore of interest to know whether DVIM possesses an enzymatic activity similar to that of influenza $\mathrm{C}$ virus.

In this report, we describe the AE activity associated with DVIM and compare it with the enzyme of other strains of $\mathrm{MHV}$ and of influenza $\mathrm{C}$ virus. We also describe the isolation and characterization of the HE protein of DVIM.

\section{Materials and methods}

\section{Viruses and cells}

Murine coronavirus strains DVIM, MHV-2, MHV-3, MHV-4 and MHV-S were grown in DBT cells using Eagle's MEM supplemented with 7\% newborn calf serum (GIBCO) and $3 \%$ tryptose phosphate broth (DIFCO) and purified as described previously [24, 25]. The influenza C/Miyagi/77 virus and the influenza A/Kumamoto/72 (H3N2) virus were grown in the amniotic and allantoic cavities of embryonated eggs and purified respectively.

\section{Acetylesterase (AE) assay}

Assays were carried out as described by Vlasak et al. [29]. In brief, purified virus suspended in $50 \mu$ l of Dulbecco's PBS (pH 7.4) was mixed with $250 \mu$ l of bovine submaxillary mucin (BSM: type I, Sigma: $25 \mathrm{mg} / \mathrm{ml}$ ) and incubated at $37^{\circ} \mathrm{C}$ for the times indicated. The released acetate was determined using the testkit 'F-kit' (Boehringer-Mannheim). As an alternative to the bovine mucin, the plasma membranes obtained from enterocytes and/or hepatocytes of $\mathrm{Balb} / \mathrm{c}$ mice were used as a substrate for the enzyme of DVIM. The methods for membrane preparation are described below. For more deteiled characterization of the AE of DVIM, the synthetic low-molecular weight substrates p-nitrophenyl acetate (:p-NiA, Eastman Kodak) and $\alpha$-naphthyl acetate (: $\alpha$-NA, Wako, Osaka, Japan) were used. Hydrolysis of p-NiA was carried out according to Vlasak et al. [30] and monitored at $\mathrm{OD}_{400}$ with a spectrophotometer (Hitachi 150-20). Diisopropyl fluorophosphate (:DFP, Wako, Osaka, Japan) was used as an inhibitor of the AE. For hydrolysis of another synthetic substrate: $\alpha$-NA, purified virus $(100 \mu \mathrm{g})$ was incubated at room temperature (approx. $25^{\circ} \mathrm{C}$ ) for $10 \mathrm{~min}$ in a $3 \mathrm{ml}$ cuvette, containing $1.0 \mathrm{mM} \alpha-\mathrm{NA}$ in PBS of $1.0 \%$ ethanol at $\mathrm{pH}$ 7.4. The quantification of substrate was monitored directly at $\mathrm{OD}_{220}$ using a spectrophotometer. 


\section{Hemagglutination (HA)}

HA assays were carried out in V-shaped microtiter plates as described previously [24], using $0.5 \%$ ( $\mathrm{vol} / \mathrm{vol}$ ) erythrocytes of mice (Balb/c); in PBS ( $\mathrm{pH} 7.2$ ) supplemented with $0.3 \%$ bovine serum albumin (BSA: Sigma). The titer was recorded as a reciprocal of the highest dilution causing a detectable HA.

\section{Preparations of plasma membranes and westernblotting analysis}

Balb/c AJcl (Clea Japan Inc.) mice were used for the preparation of plasma membranes. The livers and small intestines which were obtained from 7 days and 100 days old mice were dissected, rinsed or flushed with Dulbecco's PBS (pH 7.4) at $4{ }^{\circ} \mathrm{C}$ and stored at $-70^{\circ} \mathrm{C}$. For a preparation of plasma membranes from enterocytes, we applied the method of Kesseler et al. [13]. After homogenization of the small intestine, we obtained the supernatant by low speed centrifugation. Membranes were fractionated by precipitated with $10 \mathrm{mM} \mathrm{CaCl} 2-\mathrm{PBS}$ and differential centrifugation $(27000 \times \mathbf{g}, 30 \mathrm{~min})$. For preparation of plasma membranes from hepatocytes we applied the method descibed by Emmelot et al. [5] comprising homogenization of tissue, filtration, and three stages of differential and isopycnic centrifugation (stepwise sucrose gradient : $53.4 \% / 48.0 \% / 42.9 \% /, 70000 \times \mathbf{g}$, $90 \mathrm{~min}$ ). Plasma membranes were stored in a TE buffer $(10 \mathrm{mM}$ Tris- $\mathrm{HCl}, \mathrm{pH} 7.4,1 \mathrm{mM}$ EDTA $)$ at $-70^{\circ} \mathrm{C}$.

Western blotting was carried out by the method of Boyle et al. [1]. The amount of total membrane protein was determined by Bradford's method [2]. The IgG of anti-viral rabbit sera directed against each strain of MHV was purified through a protein A conjugated affinity column (Pharmacia). After dialysis in 0.1 M PBS (pH 7.4), the anti-serum was loaded onto the column and eluted using elution buffer ( $0.1 \mathrm{M}$ glycine- $\mathrm{HCl}, \mathrm{pH} 3.0)$, then dialyzed against Dulbecco's PBS (pH 7.4) prior to the ABC kit (ABC-GO kit, Vector Lab.) assay. Purified virions $(70 \mu \mathrm{g} / \mathrm{ml}$ ) were solubilized in $0.05 \mathrm{M}$ Tris-HCl buffer ( $\mathrm{pH} 6.8)$ with $1 \%$ SDS, $10 \%$ glycerol, $0.01 \%$ bromophenol blue and with or without $5 \%$ 2-mercaptoethanol and analyzed by SDS-polyacrylamide (12.5\%) gel electrophoresis (PAGE) after boiling in water for $3 \mathrm{~min}$. Gels were electroblotted onto a nitrocellulose membrane (Clear Blot Membrance-P, ATTO, Tokyo, Japan) using a transblot cell apparatus (ATTO, Tokyo, Japan). The membrane was then blocked with $0.5 \%$ non-fat dry milk-albumin $\left(\mathrm{pH} \mathrm{7.4)}\right.$ for $1 \mathrm{~h}$ at $25^{\circ} \mathrm{C}$ with gentle rocking. After rinsing twice with $0.05 \%$ Tween 20-PBS buffer (TPBS, pH 7.4), the membrane was incubated with gradient purified virions in TPBS for $1 \mathrm{~h}$, at $25^{\circ} \mathrm{C}$. After three washes with TPBS (10 min for each washing) the membrane was incubated with anti-MHV specific rabbit IgG and with a biotinylated anti-rabbit IgG goat antibody. The membrane was further incubated with glucose-oxidase using an ABC-GO kit (Vactor Lab.) at $4{ }^{\circ} \mathrm{C}$ and stained with nitro-blue tetrazolium (NBT). The M.W. of proteins were determined with M.W. standard markers (Bio-Rad).

\section{Protein labeling with $\left[{ }^{3} \mathrm{H}\right]-\mathrm{DFP}$ and $\left[{ }^{35} \mathrm{~S}\right]$-methionine}

Viral protein $(140 \mu \mathrm{g})$ was labeled with $0.1 \mathrm{mM}\left[{ }^{3} \mathrm{H}\right]$-DFP $(4.4 \mathrm{Ci} / \mathrm{mmol}$; NEN) in vitro according to the methods described by Vlasak et al. [30]. Metabolic protein labeling with [ ${ }^{35} \mathrm{~S}$ ]methionine was carried out as described previously [25]. Labeled virus was purified on a linear 20 to $60 \%$ sucrose gradient, and $5 \mu \mathrm{g}$ aliquots were analyzed by SDS-polyacrylamide (12.5\%) gel electrophoresis (PAGE) with or without 1\% 2-mercaptoethanol. After electrophoresis, the gels were fixed, soaked in amplifier (Amersham), dried and fluorographed at $-70^{\circ} \mathrm{C}$.

\section{Isolation of HE glycoproteins from DVIM}

Isolation of viral glycoprotein was performed according to the methods described by Sturman et al. [21]. Gradient purified virus was mixed with a TMEN-6 buffer (0.05 M Tris-maleate, 
$1 \mathrm{mM}$ EDTA, $0.1 \mathrm{M} \mathrm{NaCl}, \mathrm{pH}$ 6.0), and nonionic detergent NP-40 was added to a final concentration of $0.25 \%$. After stirring for $60 \mathrm{~min}$ at room temperature, the protein was concentrated by ultrafiltration (CENTRISART-I, Sartorius), then purified by linear sucrose gradient centrifugation (15-50\%: w/v containing of $0.1 \%$ NP-40 in TMEN-6 buffer, $150000 \times \mathbf{g}, 4{ }^{\circ} \mathrm{C}, 16 \mathrm{~h}$ ) and fractionated from the top of the tube.

\section{Preparation of monoclonal antibodies ( $m A b s)$}

A female Balb/c AJcl (Clea Japan Inc.) mouse (9-weeks old) was immunized subcutaneously (SC) with gradient purified gp69 of DVIM $(180 \mu \mathrm{g} / 100 \mu \mathrm{l})$ mixed with $100 \mu \mathrm{l}$ of complete Freund's adjuvant (DIFCO). On the 14th day, a second subcutaneous injection was applied with the same volume but with incomplete Freund's adjuvant. On the 28th and/or 38th day, a third/fourth subcutaneous injection followed with the same volume containing no adjuvant. The mouse was boosted on the 70th day post immunization with $320 \mu \mathrm{g}$ protein of gradient purified gp69. The mouse was sacrified on the 74th day and the serum was obtained from the venous axillary vein and used as a positive control serum. The spleen cells of immunized mice were fused on the 4th day after the booster injection with the P3U-1 myeloma cells using polyethylene glycol (PEG 4000: Boehringer Mannheim). Murine hybridoma cells were distributed to 96-well microplate (NUNC) at approx. $1 \times \sim 10^{5}$ cells/well in serum free media S-Clone CM-B (Sanko Junyaku Co. Ltd.) with supplement (Boehringer Mannheim) HATmedia and cultured for 4 days at $37{ }^{\circ} \mathrm{C}$ in $5 \% \mathrm{CO}_{2}$. An initial screening of hybridoma was performed by an HAI assay for detection of antibodies directed against gp69. Samples of 100 $\mu \mathrm{l} /$ well containing $25 \mu \mathrm{l}$ of DVIM (approx. $100 \mathrm{TCID}_{50} / 0.1 \mathrm{ml}$ ), two drops $(50 \mu \mathrm{l})$ of $0.5 \%$ (v/v) mouse RBC and $25 \mu 1$ of cultured fluid of each hybridoma clones, were incubated at $4{ }^{\circ} \mathrm{C}$ for $12 \mathrm{~h}$. The clones that caused a positive HAI reaction, were selected and used for the secondary screening. The titer of each antibody was determined by the limiting dilution method. The mAbs were purified by the ammonium sulfate precipitation and dialyzed against PBS ( $\mathrm{pH}$ 7.4) prior to use. The isotypes of all $\mathrm{mAbs}$ were determined as $\mathrm{IgG}_{1} / \mathrm{k}$ by $\mathrm{mAb}$ isotyping kit (Amersham).

\section{Results}

\section{Acetylesterase activity and affinity labeling of the HE protein of DVIM}

We previously reported that DVIM possesses an RDE that is different from a neuraminidase, the RDE of influenza A and B viruses [24, 25]. It was of interest whether the RDE activity of DVIM is an O-acetylesterase (EC 3,1,1,53) similar to the RDE of influenza $\mathrm{C}$ virus [8]. To analyze of RDE of DVIM, we examined for $\mathrm{AE}$ activity using natural (:BSM) and synthetic (:p-NiA, : $\alpha-\mathrm{NA})$ substrates as described by Vlasak et al. [27-30]. In Figs. 1, 2 and 3, the reaction kinetics are shown and compared to that of influenza $\mathrm{C}$ virus and several strains of $\mathrm{MHV}$. Both DVIM and influenza C/Miyagi/77 virus released detectable amounts of acetate from the natural substrate: BSM (Fig. 1). Strains of MHV-2 and MHV-S only showed a week reaction, though a higher virus-concentration was used than in the case of influenza C virus. DVIM hydrolyzed O-acetylester bonds of the synthetic substrate: $p$-nitrophenyl acetate at a much higher rate than did influenza C-Miyagi/77 virus (Fig. 2). The AE activity of DVIM was shown to be proportional to the virus-concentration and completely inhibited by DFP (diisopropyl fluoro phosphate, inset of Fig. 2). An interesting observation was that MHV-S had the highest reactivity of all strains tested with the synthetic substrate: $p$-NA though 

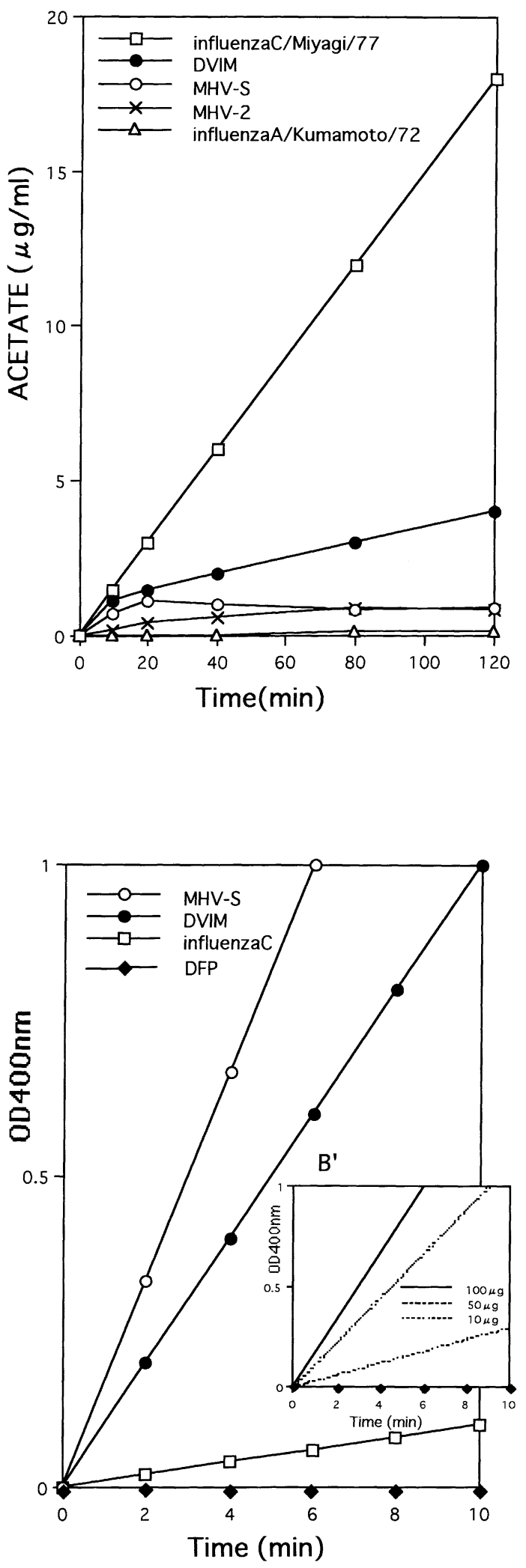

Fig. 1. AE activity of DVIM, different strains of MHV and influenza viruses. AE activity using bovine submaxillary mucin as a substrate. Purified virus: DVIM (50 $\mu \mathrm{g})$, MHV-2 $(20 \mu \mathrm{g})$, MHV-S $(50 \mu \mathrm{g})$, influenza C/Miyagi/77 (14 $\mu \mathrm{g})$ and influenza A/Kumamoto/72 $(50 \mu \mathrm{g})$, was mixed with $25 \mathrm{mg}$ of bovine submaxillary mucin in 300 $\mu l$ PBS and incubated for the times indicated. Released acetate was monitored by a test Kit (Boehringer Mannheim)

Fig. 2. AE activity assays using of pnitrophenyl acetate as a substrate. Purified virus $(50 \mu \mathrm{g})$ was incubated at room temmmperature (ca. $25^{\circ} \mathrm{C}$ ) for $10 \mathrm{~min}$ in $3 \mathrm{ml}$ cuvettes containing $1 \mathrm{mM} \mathrm{p}$ nitrophenylacetate in PBS-1\% acetonitril. Hydrolysis of the chromogenic substrate was monitored at $\mathrm{OD}_{400}$ using a chart recorder. Inset shows the hydrolysis pattern by DVIM for p-nitrophenylacetete under the same conditions, except for virus concentrations (as indicated). For DFP treatment, $50 \mu \mathrm{g}$ of DVIM was preincubated with $1 \mathrm{mM}$ DFP for $10 \mathrm{~min}$ at room temperature and used in assay 


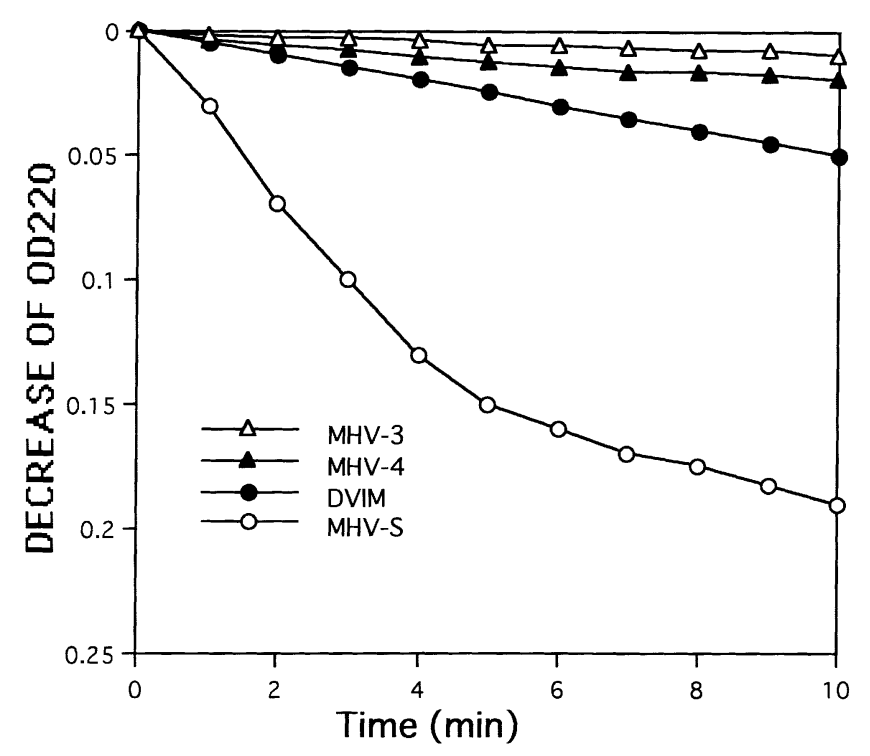

Fig. 3. AE activity using $\alpha$-naphthylacetate as a substrate. Purified virus $(100 \mu \mathrm{g})$ was incubated at room temperature (ca. $25^{\circ} \mathrm{C}$ ) for $10 \mathrm{~min}$ in $3 \mathrm{ml}$ cuvettes, containing $1 \mathrm{mM}$ $\alpha$-naphthylacetate in PBS of $1 \%$ ethanol. Decrease of the substrate was monitored directly at $\mathrm{OD}_{220}$ using a chart recorder

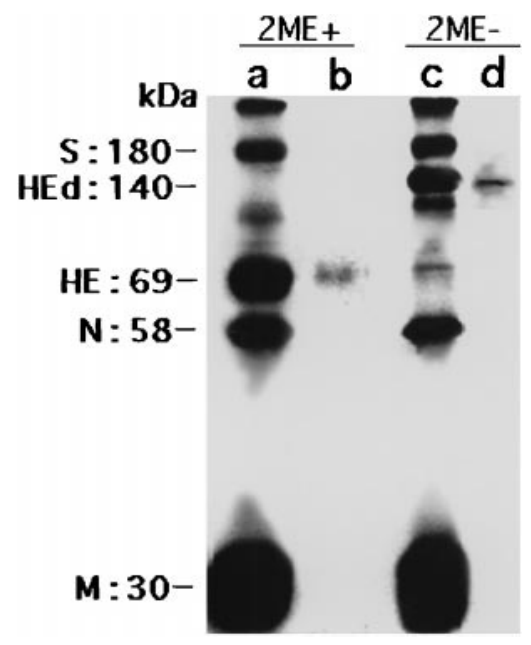

Fig. 4. Analysis of the ${ }^{3} \mathrm{H}$-DFP labeled proteins of DVIM. ${ }^{35} \mathrm{H}$-DFP labeled and ${ }^{35} \mathrm{~S}$-methionine labeled virions were analyzed by SDS-12.5 (\%) PAGE, after solubilization in a sample loading buffer with $(a, b)$ or without $(c, d)$ 2-mercaptoethanol. $a, c{ }^{35} \mathrm{~S}$-methionine labeled virions. $b, d^{3} \mathrm{H}$-DFP labeled virions. The positions of the viral proteins are indicated by approx. M.W. (in kDa)

only a trace reactivity was detected with the natural substrate BSM. A weak reaction was also detected in this system with MHV-4, but not with MHV-2, MHV-3 or with influenza A/Kumamoto/72 virus. Furthermore, when $\alpha$-NA was used as a substrate for the viral AE activity, MHV-S showed a remarkable reactivity. The other four MHVs also hydrolyzed this substrate (Fig. 3), but the reaction rates of DVIM, MHV-4 and MHV-3 were far lower than that of MHV-S. No reaction was detected on the influenza $\mathrm{C}$ virus strain $\mathrm{C} / \mathrm{Miyagi} / 77$, although significant activ- 
A.

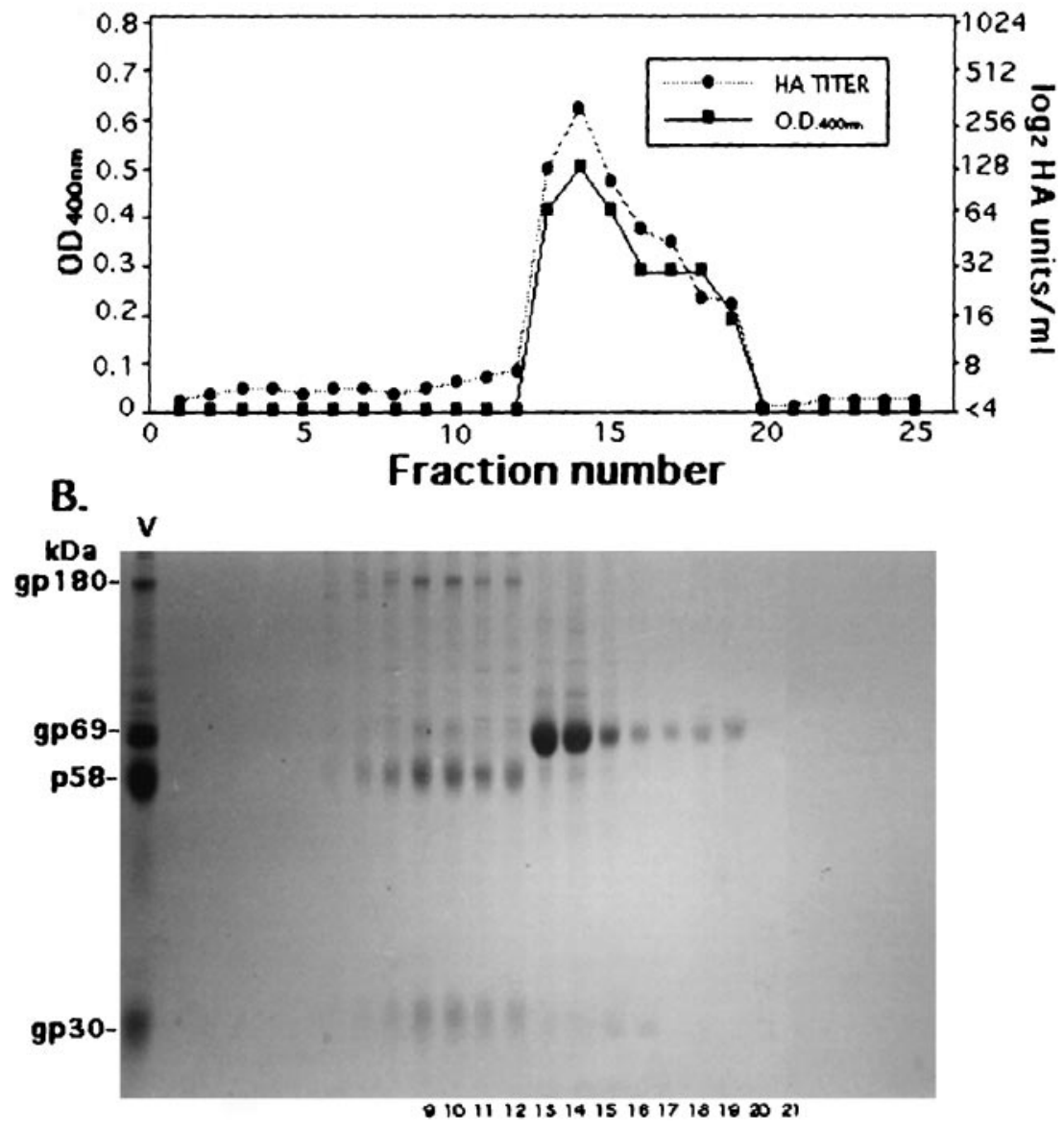

Fig. 5. Isolation of the HE of DVIM by solubilization with NP-40 followed by sucrose gradient centrifugation. A Sucrose gradients were fractionated from the top and acetylesterase activity (-O) and HA activity (-O-) were determined as described in Materials and methods. B SDS-PAGE (12.5\% acrylamide gel, with 2-mercaptoethanol) of the sucrose gradient fractions, stained with Coomassie brilliant blue. $V$ Polypeptide pattern of whole virions

ity of influenza $\mathrm{C}$ virus (strain Johannesburg) had been reported elsewhere [16]. These results indicate that the acetylesterase of DVIM has a different substrate specificity than the enzymes of MHV-S and influenza $\mathrm{C}$ virus.

To assign the AE activity to a polypeptide of DVIM, we carried out an affinity labeling of DVIM with ${ }^{3} \mathrm{H}-\mathrm{DFP}$ in vitro. After purification, DVIM was analyzed on SDS-12.5\% PAGE with or without 2-mercaptoethanol. A single labeled protein was detected migrating with an approximately MW of 69kDa under reducing conditions and with an approximate MW of $140 \mathrm{kDa}$ under non-reducing conditions (Fig. 4). These results indicate that ${ }^{3} \mathrm{H}-\mathrm{DFP}$ labeled protein of DVIM has the same migration characteristics as the ${ }^{35} \mathrm{~S}$-methionine labeled HE perotein. 


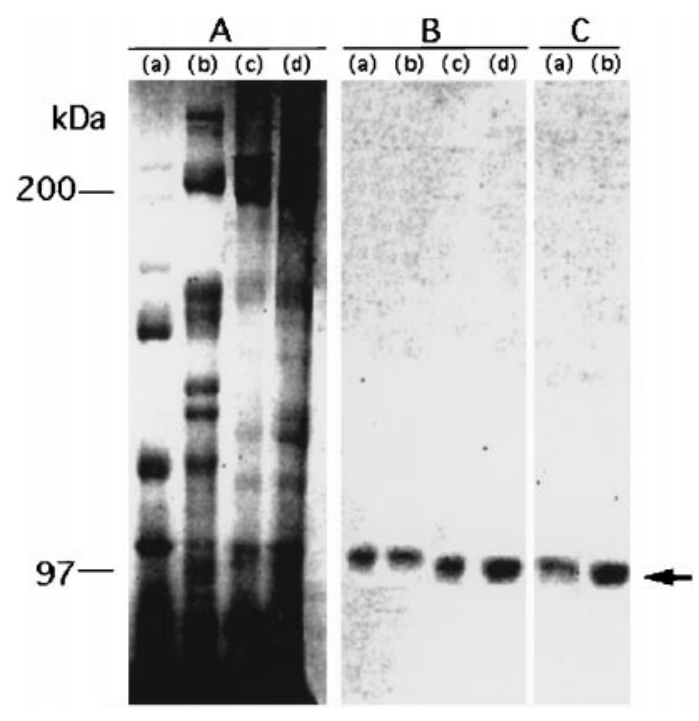

Fig. 6. DVIM-binding proteins located on the plasma membranes from enteric and hepatic cells. A PAGE pattern of plasma membrane of the DVIM specific tissue (small intestine and liver of Balb/c mice) obtained by SDS-8(\%) gel electrophoresis in the presence of 2mercaptoethanol and stained with Coomassie blue. $a$ Infant enteric cells. $b$ Adult enteric cells. $c$ Infant hepatic cells. $d$ Adult hepatic cells. B VOPBA of the same samples as A was performed by incubation of DVIM with membrane proteins electroblotted to nitrocellulose and stained as described in Materials and methods. $a$ Infant enteric cell. $b$ Infant hepatic cells. $c$ Adult enteric cells. $d$ Adult hepatic cells. C VOPBA carried out as shown in B using strain: MHV-4 and MHV-S and specific antiserum. $a$ Adult hepatic cells with MHV-4, $b$ adult hepatic cells with MHV-S. Arrow shows virus-binding band of approximately M.W.

$(110 \mathrm{kDa})$

\section{Isolation of the HE proteins from the DVIM}

The HE (:gp69) of DVIM was isolated in solubilized form by treatment with the non-ionic detergent (NP-40), and purified as described above. After dialysis, each fraction was assayed for AE and HA activities (Fig. 5A). The purity of each fraction was tested by SDS-PAGE (Fig. 5B). The HA activity was found to be proportional to the concentration of the HE glycoprotein. The HA activity in each fractioned paralleled the AE activity. This result is different from the result of a similar analysis reported for BCV. The acetylesterase activity of BCV also copurified with the HE protein [17]. However, the major HA activity has been reported to be associated with the S protein [18]. The S protein of DVIM, on the other hand, was found to be devoid of hemagglutinating activity (Fig. 5A, fractions 9-12). Immunoreactivity of isolated HE protein was demonstrated by electron microscopy using negative staining combined with monoclonal antibody [\#3a28] and colloid gold methods. Approximately $5 \mathrm{~nm}$ globular structures are visible distinctly apart from the aggregates (data not shown). 


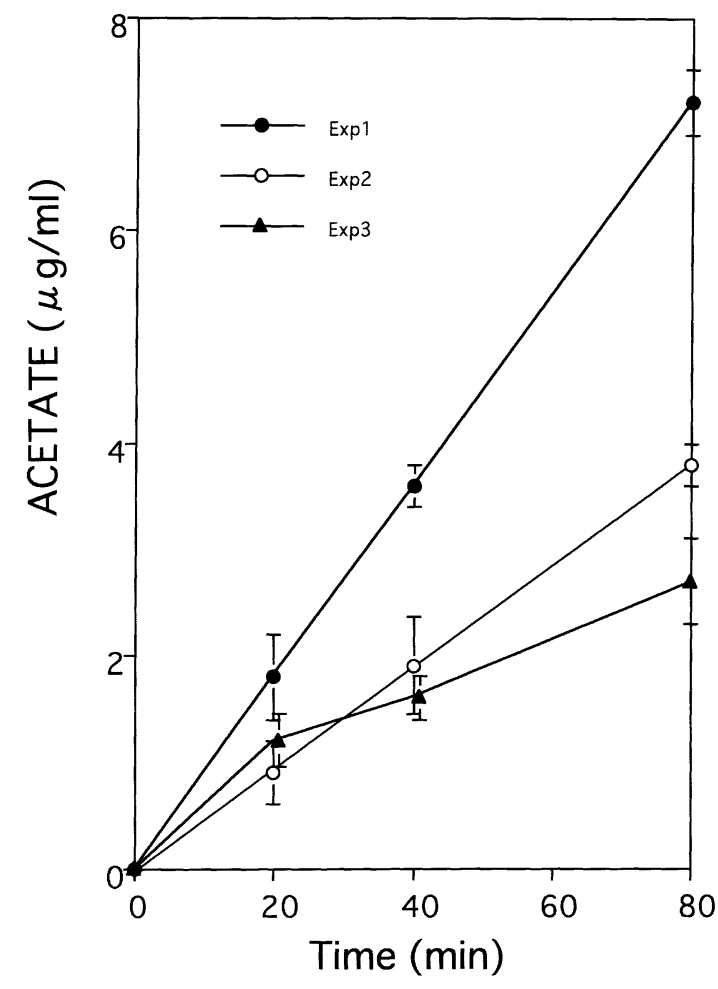

Fig. 7. Acetylesterase activity of DVIM, assayed with enterocytic and/or hepatocytic plasma membranes obtained from adult mice $(\mathrm{Balb} / \mathrm{c})$. The gradient purified virus $(40 \mu \mathrm{g})$, was incubated with the preparation of the plasma membranes obtained from adult mice at $37^{\circ} \mathrm{C}$ for the time indicated. The released acetate was determined by the test kit as shown in Fig. 1. The results were presented as the mean $+\mathrm{SD}$ of several assays. The concentration of plasma membranes was shown in parenthesis for each experiment. Exp 1 Brush border membranes (BBM: $100 \mathrm{mg} / \mathrm{ml}$ ) of enterocytes. Exp 2 BBMs of enterocytes $(50 \mathrm{mg} / \mathrm{ml})$. Exp 3 Hepatic cell membranes $(50 \mathrm{mg} / \mathrm{ml})$. Controls, carried out without plasma membranes, showed no release of acetate

\section{Identification of the DVIM-binding proteins detected on target-tissues}

By the histopathological studies of DVIM infected mice, we have found intensive disorders in the small intestine and the liver (unpubl. data). Therefore, it was of interest to detect the receptors of DVIM within the plasma membrane of sensitive tissues: intestinal brush border and liver hepatocyte. Figure 6A shows the PAGE pattern of the plasma membrane proteins stained with Coomassie blue. This result indicated that virus-binding is only detectable to a minor component of the intestinal membranes. The protein pattern of enterocytic membranes may reflect an age-specific variability of membrane proteins during development of animals (Fig. 6A, lane a and b). No ontogenetic differences was detected in the membrane proteins of hepatocytes (Fig. 6A, B). Our preliminary data showed that the receptors for DVIM are sensitive to proteases but not affected by lipid-solvents. In order to determine which membrane proteins can serve as virus receptors, we carried out a virus overlay protein binding assay and identified a single virus-binding protein of approximately $110 \mathrm{kDa}$ [31] (Fig. 6B). This protein was present in both enterocytes and hepatocytes and a protein of the same size was recognized by MHV-4 and MHV-S (Fig. 6C). These results suggest DVIM recognizes the same $110 \mathrm{kDa}$ protein that has originally been described as receptor for MHVA59 [31]. We then examined whether the plasma membranes from target-tissues can serve as substrates for the AE of DVIM. We found that plasma membranes enterocytes and hepatocytes are suitable substrates for the AE as indicates by the 
release of acetate (Fig.7). In fact, the reactivity of AE for theses membranes was higher than the reactivity for another natural substrate, BSM.

\section{Discussion}

Our studies have shown that DVIM has an acetylesterase activity that is a function of the HE protein. A similar finding has been reported for BCV [22, 28, 29] and some strains of MHV [26, 32] while other strains of MHV lack a comparable enzyme. Among murine coronaviruses with an HE protein, DVIM has a unique position. The substrate specificity of the acetylesterase of DVIM was different from the other viruses analyzed. Furthermore, DVIM is the only murine coronavirus that is able to agglutinate erythrocytes [26]. In this respect, DVIM resembles viruses like BCV and human coronavirus OC43 [28]. However, in the case of these two viruses, hemagglutinating activity has been assigned to both the $\mathrm{HE}$ and the $\mathrm{S}$ protein the latter being more efficient in agglutinating erythrocytes than the former protein [18]. We have demonstrated here that the hemagglutinating activity of DVIM is a function of the HE protein, whereas the S protein is devoid of such an activity. This difference between DVIM and BCV may be related to the possibly that only BCV, not DVIM, uses the sialic acid binding activity to initiate infection of cultured cells [19]. DVIM on the other hand has a receptor binding activity that is similar to that of other murine coronaviruses [7]. In virus overlay binding assays with membrane proteins of enterocytes and hepatocytes, virus binding was detectable only to $110 \mathrm{kDa}$ protein. A protein of this size has been reported to serve as a receptor also for other strains of MHV [31]. This protein that has been identified by others as biliary glycoprotein also mediates infection by DVIM. This finding and the fact that most strains of MHV lack an HA activity and some strains lack an HE protein and an acetylesterase suggest that the HE protein and its biological activities are dispensible for virus growth in cell culture. On the other hand, it is interesting to note that a murine coronavirus with a pronounced enterotropism has retained these activities [15, 23, 24]. Moreover, no mutant of variant of DVIM has been described that has lost the biological activities of the HE protein but retained the enterotropism. Therefore, the HE protein may be required not for growth in cell culture, but for infection of the intestine. There are several ways how the HE protein may contribute to the enterotropism of DVIM. It may have an accessory function in finding of and binding to the cellular receptor, e.g. possibly that there are two different interaction between DVIM and the cell surface receptors, one mediated by the HE protein and sialic acid as a accessory interaction, and a second one mediated by the S protein of DVIM and $110 \mathrm{kDa}$ biliary glycoprotein. It may also help in a postattachment step, e.g. fusion between the viral and the cellular membrane. In this respect it is interesting that the highest acetylesterase activity was measured when membranes of target cells were used as substrates. The HE protein may also function in a preinfection stadium. The epithelial cells of the intestine are coveres by mucins that are rich in 9-O-acetylated sialic acid. The HE protein may help to bind to these sialylated sialoglycoconjugates and to release acetate from the 
sialic acid. In this way, the access of DVIM to the cell surface may be facilitated. More work is requied to know the actual function of $\mathrm{HE}$.

\section{Acknowledgements}

We wish to thank Drs. K. Nakamura and K. Sugawara of Yamagata University, Faculty of Medicine, Dept. of Bacteriology for their kindly gift of Influenza C viruses and Mr. E. Morita of Hirosaki University, Faculty of Science for helpful assistance of this work.

\section{References}

1. Boyle JF, Weismiller DG, Holmes KV (1987) Genetic resistance to mouse hepatitis virus correlates with absence of virus-binding activity on target tissues. J Virol 61: 185-189

2. Bradford MM (1976) A rapid and sensitive method for the quantitation of microgram quantities of protein utilizing the principle of protein-dye binding. Anal Biochem 72: 248-254

3. Bridger JC, Caul EO, Egglestone SI (1978) Relocation of an enteric bovine coronavirus in intestinal organ cultures. Arch Virol 57: 43-51

4. Bucknall RA, Kalica AR, Chanok RM (1972) Intracellular development and mechanism of hemandsorption of human coronavirus, OC43. Proc Soc Exp Biol Med 139: 811-817

5. Emmelot P, Bos CJ, Benedetti EL, Rumke PH (1964) 1. Chemical composition and enzyme content of plasma membranes isolated from rat liver. Biochem Biophys Acta 90: $126-145$

6. Formanowski F, Meier-Ewert $\mathrm{H}$ (1988) Isolation of the influenza $\mathrm{C}$ virus glycoprotein in a soluble form by bromelain digestion. Virus Res 10: 177-192

7. Gagneten S, Goutg O, Dubois-Dalco M, Rottier P, Rossen J, Holmes KV (1995) Interaction of mouse hepatitis virus (MHV) spike glycoprotein with receptor glycoprotein MHVR is required for infection with an MHV strain that express the hemagglutininesterase glycoprotein. J Virol 69: 889-895

8. Herrler G, Rott R, Klenk HD, Muller HP, Shukla AK, Schauer R (1985) The receptordestroying enzyme of influenza $\mathrm{C}$ virus is neuraminate $\mathrm{O}$-acetylesterase. EMBO $\mathrm{J} 4$ : $1503-1506$

9. Herrler G, Durkop I, Becht H, Klenk HD (1988) The glycoprotein of influenza C virus is the haemagglutinin, esterase and fusion factor. J Gen Virol 69: 839-846

10. Kapkian AZ, James HD, Kelly SJ, King LM, Vaughn AL, Chanok RM (1972) Hemadsorption by coronavirus strain OC-43. Proc Soc Exp Biol Med 139: 179-186

11. Kaye HS, Dowdle WR (1969) Some characteristics of hemagglutination of certain strains of "IBV-like" virus. J Infect Dis 120: 576-581

12. Kendal AP (1975) A comparison of "influenza C" with prototype myxoviruses; Receptordestroying activity (neuraminidase) and structural polypeptides. Virology 65: 87-99

13. Kesslar MO, Acuto O, Storelli C, Murer H, Muller M, Semenza G (1978) A monoclonal procedure for the rapid preparation of efficiently transporting vesicle from small intestinal brush border membranes. Their use to investigate some properties of D-glucose and choline transport systems. Biochem Biophys Acta 506: 136-154

14. King B, Potts BJ, Brian DA (1985) Bovine coronavirus hemagglutinin protein. Virus Res 2: 56-59

15. Sato K, Maru M, Wada T (1976) Some characteristics of corona-like virus isolated from infant mice with diarrhea and inflammatory submaxillary gland of rat. Virus 26: 97

16. Schauer R, Reuter G, Stolle S, Posadas der Rio F, Herrler G, Klenk HD (1988) Isolation and characterization of sialate 9(4)-O acetylesterase from influenza $\mathrm{C}$ virus. Biol Chem 369: 1 121-1 130 
17. Schultze B, Wahn K, Klenk HD, Herrler G (1991) Isolation HE-protein from hemagglutinating encephalomyelitis virus and bovine coronavirus has receptor-destroying and receptor-binding activity. Virology 180: 221-228

18. Schultze B, Gross HJ, Brossmer R, Herrler G (1991) The S protein of bovine coronavirus is a hemagglutinin recognize $9-\mathrm{O}$-acetylated sialic acid as a receptor determinant. J Virol 65: 6232-6237

19. Schultze B, Herrler G (1992) Bovine coronavirus use N-acetyl-9-O-acetylneuraminic acid as a receptor determination to initiate the infection of cultured cells. J Gen Virol 73: 901-906

20. Stair EL, Rhodes MB, White RG, Mebus CA (1972) Neonatal calf diarrhea - purification and electron microscopy of a coronavirus-like agent. Am J Vet Res 33: 1 147-1 156

21. Sturman LS, Holmes KV (1983) The molecular biology of coronavirus. Adv Virus Res 28: $35-112$

22. Spaan W, Gevanagh D, Horzinek MC (1990) Coronaviruses. Immunochemistry of viruses, II. The basis for serodiagnosis and vaccines. Elsevier, New York, pp 359-370

23. Sugiyama K, Amano Y (1980) Hemagglutination and structural polypeptides of a new coronavirus associated with diarrhea in infant mice. Arch Virol 66: 95-105

24. Sugiyama K, Amano Y (1981) Morphological and biological properties of new coronavirus associated with diarrhea in infant mice. Arch Virol 67: 241-251

25. Sugiyama K, Ishikawa R, Fukuhara N (1986) Structural polypeptides of the murine coronavirus DVIM. Arch Virol 89: 245-254

26. Talbot PJ (1989) Hemagglutination by murine hepatitis viruses. Intervirology 30: 117120

27. Vlasak R, Kryatal M, Nacht M, Palese P (1987) The influenza C virus glycoprotein (HE) exhibits receptor-binding (hemagglutinin) and receptor-destroying (esterase) activities. Virology 160: 419-425

28. Vlasak R, Luytjes W, Spaan W, Palese P (1988) Human and bovine coronaviruses recognize sialic acid containing receptors similar to those of influenza $\mathrm{C}$ viruses. Proc Natl Acad Sci USA 85: 4526-4 529

29. Vlasak R, Luytjes W, Leider J, Spaan W, Palese P (1988) The E3 protein of bovine coronavirus is a receptor-destroying enzyme with acetylesterase activity. J Virol 62: 4686-4 690

30. Vlasak R, Muster T, Lauro AM, Powers JC, Palese P (1989) Influenza C virus esterase: analysis of catalytic site, inhibition, and possible function. J Virol 63: 2 056-2 062

31. Williams RK, Jiang G-S, Snyder SW, Frana MF, Holmes K (1990) Purification of the 110-kilodalton glycoprotein receptor for mouse hepatitis virus (MHV)-A59 from mouse liver and identification of a nonfunctional, homologous protein in MHV-resistant SJL/J mice. J Virol 64: 3817-3823

32. Yokomori Y, Monica N, Makino S, Shieh CK, Lai MC (1989) Biosynthesis, structure, and biological activities of envelope protein gp65 of murine coronavirus. Virology 173: 683-691

33. Zhang X, Konstain GK, Storz J (1992) The hemagglutinin/esterase gene of human coronavirus strain OC43: phylogenetic relationships to bovine and murine coronavirus and influenza C virus. Virology 186: 318-323

Authors' address: Dr. K. Sugiyama, Department of Biology, Faculty of Science, Hirosaki University, Hirosaki 036, Japan. 